\title{
AÇÃO DE GIBERELINAS E CITOCININAS NA GERMINAÇÃO DE SEMENTES DE PESSEGUEIRO
}

\author{
GIBBERELLINS AND CYTOKININS EFFECTS ON PEACH SEED \\ GERMINATION
}

\author{
Luciano PICOLOTTO ${ }^{1}$ \\ Valmor João BIANCHI ${ }^{2}$ \\ José Carlos FACHINELLO ${ }^{3}$
}

\begin{abstract}
RESUMO
Uma satisfatória germinação e a redução no período de formação do porta-enxerto para qualquer espécie frutífera é desejável quando se visa a redução dos custos de produção do viveirista. O objetivo do presente trabalho foi avaliar a ação dos reguladores vegetais do grupo das citocininas associado ao grupo das giberelinas na germinação de sementes de pessegueiro (Prunus persica (L.) Batsch), sem endocarpo. Utilizaram-se sementes dos cultivares Okinawa, Capdeboscq e Tsukuba. Os produtos comerciais contendo reguladores vegetais usados foram Promalina ${ }^{\circledR}\left(\right.$ benziladenina $\left.+\mathrm{GA}_{4+7}\right)$ e Pro-Gibb ${ }^{\circledast}\left(\mathrm{GA}_{3}\right)$ nas concentrações $0,100,200$ e $300 \mathrm{mg} \mathrm{L}^{-1}$, dos princípios ativos. As sementes foram colocadas em placas de Petri, forradas com folha de papel filtro umedecido com solução fúngica e bactericida e mantidas à temperatura ambiente $\left(21^{\circ} \mathrm{C}\right)$. $\mathrm{O}$ Capdeboscq obteve a melhor resposta quanto à porcentagem de germinação e à velocidade de emergência, em todas as concentrações de ambos os reguladores vegetais. Os tratamentos com 200 e $300 \mathrm{mg} \mathrm{L}^{-1}$, utilizando o regulador vegetal contendo benziladenina $+\mathrm{GA}_{4+7}$, proporcionaram a maior porcentagem de germinação $(80,0 \%$ e $78,3 \%$, respectivamente) e maiores índices de velocidade de germinação diários $(0,078$ e 0,081 , respectivamente).

Palavras-chave: Porta-enxertos; propagação sexuada; reguladores vegetais; dormência.
\end{abstract}

\begin{abstract}
A satisfactory seed germination followed by a promptly seedling formation, for any fruits species, is desired when aiming reductions at nursery production costs. The research aimed to assess the role of plant regulators (cytokinin associated to gibberellin group) on peach seed germination (Prunus persica (L.) Batsch) without endocarp. It was used seed of cultivars Okinawa, Capdebosca e Tsukuba. The commercial products applied were Promalina ${ }^{\circledast}\left(\right.$ benziladenina $+\mathrm{GA}_{4+7}$ ) and $\operatorname{Pro}^{-G i b b}{ }^{\boxplus}\left(\mathrm{GA}_{3}\right)$ at 0, 100, 200 and 300 $\mathrm{mg} \mathrm{L}^{-1}$ of the active principle. The seeds were set in Petri dishes lined with filter paper previously moistened in an aqueous solution of fungicide and bactericide and kept at room temperature $\left( \pm 21^{\circ} \mathrm{C}\right)$. 'Capdeboscq' provided the best results regarding to seed germination and emergence velocity, at all concentrations of both plant regulators. The use of benziladenina $+\mathrm{GA}_{4+7}$ at 200 and 300 $\mathrm{mg} \mathrm{L}^{-1}$ provided the highest germination percentage $(80,0 \%$ and $78,3 \%$, respectively), and highest index of daily germination velocity (0,078 and 0,081, respectively).

Key-words: rootstocks; sexual propagation; plant regulators and dormancy.
\end{abstract}

\footnotetext{
${ }^{1}$ Engenheiro Agrônomo, Doutorando do PPGA, área de concentração em Fruticultura de Clima Temperado. Faculdade de Agronomia Eliseu Maciel/Universidade Federal de Pelotas. Caixa postal 354, 96010-900, Pelotas, RS. E-mail: picolotto@gmail.com

2 Engenheiro Agrônomo, Dr., Professor Adjunto do Departamento de Botânica, IB/UFPel. E-mail: valmorjb@yahoo.com

${ }^{3}$ Engenheiro Agrônomo, Dr., Professor Titular do Departamento de Fitotecnia, FAEM/UFPel. E-mail: fachi@ufpel.tche.br
} 


\section{INTRODUÇÃO}

No Brasil, a área plantada com pessegueiro (Prunus persica (L.) Batsch.) é de aproximadamente $21 \mathrm{mil} \mathrm{ha}^{-1}$. O Estado do Rio Grande do Sul é o maior produtor, possuindo 13.824 ha de pêssego de mesa e de indústria (FACHINELLO et al., 2005). No Brasil, a produtividade média do pêssego varia entre 5 a 10 t ha ${ }^{-1}$. Para MARTINS (2005), dentre as espécies frutíferas de clima temperado com potencial econômico no Brasil, o pessegueiro é uma cultura importante, com produção da ordem de $200.000 \mathrm{t}$ $a^{-1}$. A cultura do pessegueiro é distribuída nos Estados do Rio Grande do Sul, Santa Catarina, São Paulo, Paraná e Minas Gerais (AGRIANUAL, 2004). Conforme CHALFUN e HOFFMANN (1997), a expansão dos plantios e aumento da produção dessa espécie depende de fatores tais como a produção de mudas de qualidade e de baixo custo.

A propagação dos porta-enxertos desta espécie frutífera é realizada, principalmente, através de semente (CHALFUN e HOFFMANN, 1997). Segundo SIMÃO (1998) as sementes de pessegueiro, devido a dormência, necessitam de um período de repouso a baixa temperatura para germinar. Sob ação de baixa temperatura durante o inverno, ou de câmara frigorífica e de umidade (86\%), a amêndoa completa a sua maturação fisiológica. No entanto, a exposição dos caroços a baixa temperatura durante o inverno geralmente não gera germinação satisfatória, chegando segundo FISCHER (Frutiplan Produção de Mudas, Pelotas, RS, informação verbal) a aproximadamente $50 \%$.

Segundo CHALFUN e HOFFMANN (1997), pode-se associar o método que utiliza reguladores vegetais ao método de superação de dormência com baixa temperatura. A ação das giberelinas $\left(\mathrm{GA}_{\mathrm{s}}\right)$ ou dos ácidos giberélicos no processo germinativo é bem conhecido, segundo METIVIER (1979) as mesmas atuam no controle da hidrólise do tecido de reserva para o fornecimento de energia ao embrião, promovendo, de acordo com SALISBURY e ROSS (1992) o alongamento celular, fazendo a radícula se desenvolva-se através do endosperma ou tegumento.

No entanto, há outros reguladores vegetais envolvidos no processo da germinação, como as citocininas que têm a capacidade de promover a germinação em algumas espécies (METIVIER, 1986). Para a cultura do pessegueiro essa capacidade das citocininas promover a germinação ainda é pouco conhecida. As mesmas estimulam a divisão celular (TAIZ e ZEIGER, 2004), apresentando ação contrária àquela dos inibidores; são substâncias essenciais para complementar a ação das giberelinas na indução da germinação e de processos enzimáticos, quando estes são bloqueados por inibidores (FRAGA, 1982).

O objetivo do presente trabalho foi avaliar a porcentagem de germinação de sementes de portaenxertos de pessegueiro submetidas ao tratamento com citocininas associadas com giberelinas.

\section{MATERIAL E MÉTODOS}

O experimento foi desenvolvido no laboratório de caracterização molecular de plantas lenhosas, do setor de fruticultura da Faculdade de Agronomia Eliseu Maciel, Universidade Federal de Pelotas, em fevereiro de 2005. Foram utilizadas sementes de porta-enxertos de pessegueiro dos cultivares Okinawa, Tsukuba e Capdeboscq. Os dois primeiros cultivares foram utilizados devido sua resistência a nematóides causadores de galhas, já o cv. Capdeboscq devido facilidade de obtenção e boa germinação.

Os reguladores vegetais usados foram Pro$\mathrm{Gibb}^{\circledR}\left(\mathrm{GA}_{3}\right)$, contendo $10 \%$ de $\mathrm{GA}_{3}$ e Promalina ${ }^{\circledR}$, contendo $1,8 \%$ de benziladenina (BA) mais $1,8 \%$ de $\mathrm{GA}_{4+7}$. As concentrações foram 0 (testemunha), 100, 200 e $300 \mathrm{mg} \mathrm{L}^{-1}$ de princípio ativo dos respectivos reguladores vegetais.

Os frutos foram colhidos de plantas com seis anos de idade, do Banco Ativo de Germoplasma do Centro Agropecuário da Palma-UFPel, durante os meses de dezembro de 2004 e janeiro de 2005. Logo após a colheita dos frutos, realizou-se a despolpa dos caroços, lavagem e secagem à sombra. Seguiuse com a desinfestação com solução de fungicida procymidone (200 g de Sialex $500^{\circledR} 100 \mathrm{~L}^{-1}$ de $\mathrm{H}_{2} \mathrm{O}$ ), por uma hora.

A assepsia de todo o material utilizado no experimento (torno, bandejas contendo os caroços, pinças, luvas, entre outros) foi realizada com solução de hipoclorito de sódio ( $\mathrm{NaOCl}$ ) e álcool, 1,5\% e 70\%, respectivamente. A desinfestação das placas de Petri para colocação das sementes foi realizada pela imersão em solução de $\mathrm{NaOCl} 1,5 \%$, por um período de 24 h (BIANCHI,Departamento de Botânica, IB/ UFPel, informação verbal).

No dia da instalação do experimento, os caroços foram flambados com álcool $70 \%$, por oito segundos e a quebra dos caroços foi realizada em um torno manual, com posterior imersão das sementes em solução de $\mathrm{NaOCl}(1,5 \%)$, por um minuto, seguido de lavagem com água destilada. Os tratamentos constituíram-se de imersão (durante 16 h) das sementes em uma solução contendo os reguladores vegetais.

Após o tratamento, as sementes foram acondicionadas em placas de Petri contendo uma folha de papel filtro, umedecida com 2,0 mL placa $^{-1}$ de solução fungicida e bactericida (200 e $300 \mathrm{~g} 100$ $\mathrm{L}^{-1}$ de $\mathrm{H}_{2} \mathrm{O}$ de Sialex $500^{\circledR}$ e Agrimicina ${ }^{\circledR}$, respectivamente). Em seguida, as placas de Petri foram lacradas com parafilme e colocadas em local sem luminosidade e temperatura ambiente média de $21^{\circ} \mathrm{C}$.

Semanalmente, foram realizadas avaliações e as sementes germinadas foram transferidas para sacos plásticos $(5 \times 10 \mathrm{~cm})$ com substrato Plantmax ${ }^{\circledR}$ HT. 
PICOLOTTO, L. et al. Ação de giberelinas e citocininas...

As variáveis analisadas foram porcentagem de sementes germinadas, índice de velocidade de germinação diária $\left(I V G_{D}\right)$. As avaliações semanais, além de fornecer a porcentagem de germinação, serviram para visualizar a distribuição da germinação durante o período experimental.

A velocidade de germinação foi estimada pelo $\mathrm{IVG}_{\mathrm{D}}$ calculado ao final do período experimental, aos 49 dias, pela fórmula: IVG $\mathrm{D}_{\mathrm{D}}=\left(\mathrm{n}_{1} / \mathrm{d}_{1}\right)+\left(\mathrm{n}_{2}-\mathrm{n}_{1} / \mathrm{d}_{2}-\right.$ $\left.d_{1}\right)+\left(n_{3}-n_{2} / d_{3}-d_{2}\right)+\ldots+\left(n_{n}-n_{n-1} / d_{n}-d_{n-1}\right)$ onde: $n_{1} ; n_{2} ;$ $\mathrm{n}_{3} \ldots ; \mathrm{n}_{\mathrm{n}}$ é o número de sementes germinadas da primeira a enésima leitura e $d_{1} ; d_{2} ; d_{3} \ldots ; d_{n}$ sendo o número de dias transcorridos da semeadura até a enésima leitura (POPINIGIS, 1977).

O delineamento experimental foi, o inteiramente casualizado, adotando-se fatorial $3 \times 2 \times 4$, sendo três porta-enxertos, dois reguladores vegetais e quatro concentrações, totalizando 24 tratamentos, com quatro repetições (cinco sementes/repetição). As variáveis, porcentagem de germinação e IVG foram analisadas com dados acumulados no final do experimento, aos 49 dias.

Os dados foram submetidos à análise de variância e as médias dos tratamentos comparadas pelo teste Duncan, ao nível de significância de 5\%, mediante o uso do programa estatístico SANEST (ZONTA e MACHADO, 1995).

\section{RESULTADOS}

Para a variável porcentagem de germinação e IVG ${ }_{D}$ houve efeito significativo das interações entre os porta-enxerto + concentração e regulador vegetal + concentração.

Avaliando o efeito médio das concentrações dos reguladores vegetais sobre os três cultivares testados, verificou-se que, exceto no tratamento testemunha $\left(0 \mathrm{mg} \mathrm{L}^{-1}\right), \mathrm{o} \mathrm{cv}$. Capedboscq apresentou maior porcentagem de germinação $(72,50 \%)$ em relação aos cvs. Tsukuba e Okinawa (Tabela 1 ). Embora a maior porcentagem de sementes germinadas tenha ocorrido no tratamento com 300 $\mathrm{mg} \mathrm{L}^{-1}$ de regulador vegetal, nos cvs. Capdeboscq e Okinawa, os valores obtidos somente diferiram significativamente em relação ao tratamento testemunha $(5,01 \%$ e $2,52 \%$, respectivamente). Entretanto, para o cv. Tsukuba a maior porcentagem de germinação foi obtida no tratamento com $200 \mathrm{mg}$ $\mathrm{L}^{-1}(47,5 \%)$, não diferindo significativamente do tratamento com $300 \mathrm{mg} \mathrm{L}^{-1}$, porém, ambos foram superiores aos demais tratamentos (Tabela 1).

TABELA 1 - Porcentagem média de germinação de sementes de porta-enxertos de pessegueiro tratados com dois tipos de reguladores vegetais em diferentes concentrações. FAEM/UFPel, Pelotas-RS, 2005.

\begin{tabular}{|c|c|c|c|c|c|}
\hline \multirow[b]{2}{*}{ Fatores } & \multicolumn{5}{|c|}{ Germinação (\%) } \\
\hline & \multicolumn{4}{|c|}{------ Concentrações de regulador vegetal $\left(\mathrm{mg} \mathrm{L}^{-1}\right)$------- } & \multirow[t]{2}{*}{ Médias } \\
\hline Cultivar & 0 & 100 & 200 & 300 & \\
\hline Capdéboscq & $5,01 \mathrm{bA}^{*}$ & $65,00 \mathrm{aA}$ & $65,00 \mathrm{aA}$ & $72,50 \mathrm{aA}$ & $51,88 \mathrm{~A}$ \\
\hline Tsukuba & $0,00 \mathrm{cA}$ & $25,00 \mathrm{bB}$ & $47,50 \mathrm{aB}$ & $45,01 \mathrm{aB}$ & $29,38 \mathrm{~B}$ \\
\hline Okinawa & $2,52 \mathrm{bA}$ & $30,00 \mathrm{aB}$ & $27,50 \mathrm{aC}$ & $35,00 \mathrm{aB}$ & $23,76 \mathrm{C}$ \\
\hline Médias & $2,52 c$ & $40,00 \mathrm{~b}$ & $46,67 \mathrm{ab}$ & $50,84 a$ & \\
\hline \multicolumn{6}{|c|}{ Regulador vegetal } \\
\hline $\mathrm{BA}^{-\mathrm{GA}_{4}+7}$ & $1,68 \mathrm{cA}$ & $63,33 \mathrm{bA}$ & $80,00 \mathrm{aA}$ & $78,33 \mathrm{aA}$ & $55,84 \mathrm{~A}$ \\
\hline $\mathrm{GA}_{3}$ & $3,35 \mathrm{bA}$ & $16,67 \mathrm{aB}$ & $13,34 \mathrm{abB}$ & $23,34 \mathrm{aB}$ & $14,17 \mathrm{~B}$ \\
\hline Médias & $2,52 \mathrm{c}$ & $40,00 \mathrm{~b}$ & $46,67 \mathrm{ab}$ & $50,84 a$ & \\
\hline
\end{tabular}

* Médias seguidas de mesma letra, minúscula na linha e maiúscula na coluna, não diferem entre si pelo Teste Duncan, ao nível de $5 \%$ de probabilidade.

Dentre os reguladores vegetais utilizados, o $\mathrm{BA}+\mathrm{GA}_{4+7}$ proporcionou os melhores resultados quanto à porcentagem de germinação em relação ao $\mathrm{GA}_{3}$, em todas as concentrações testadas, exceto para os tratamentos testemunha que não diferiram entre si (Tabela 1).

Não se observou diferença significativa para a porcentagem média de germinação entre os tratamentos com as concentrações de 200 e $300 \mathrm{mg}$ $\mathrm{L}^{-1}$ de $\mathrm{BA}+\mathrm{GA}_{4+7}$, sendo superiores em relação ao tratamento com $100 \mathrm{mg} \mathrm{L}^{-1}$, e este foi superior em relação à testemunha (Tabela 1). Para o $\mathrm{GA}_{3}$, a maior porcentagem de germinação foi obtida no tratamento com $300 \mathrm{mg} \mathrm{L}^{-1}$, porém não diferindo significativamente dos tratamentos com 100 e 200 $\mathrm{mg} \mathrm{L}^{-1}$. A menor porcentagem de germinação foi obtida no tratamento testemunha $(3,35 \%)$ a qual não diferiu significativamente do tratamento com $200 \mathrm{mg}$ $\mathrm{L}^{-1}(13,34 \%)$ (Tabela 1$)$.

Com exceção do tratamento testemunha, o cv. Capbeboscq apresentou os melhores índices de velocidade de germinação (IVG $\mathrm{D}_{\mathrm{D}}$ ), em relação aos demais cultivares em função de cada concentração de regulador vegetal, porém não diferindo significativamente do cv. Tsukuba na concentração de $200 \mathrm{mg} \mathrm{L}^{-1}$ (Tabela 2). 
PICOLOTTO, L. et al. Ação de giberelinas e citocininas...

TABELA 2 - Índice de velocidade de germinação diária (IVG $)_{D}$ em sementes de três porta-enxertos de pessegueiro, tratados com dois tipos de reguladores vegetais em diferentes concentrações. FAEM/UFPel, Pelotas-RS, 2005.

\begin{tabular}{|c|c|c|c|c|c|}
\hline \multirow[b]{2}{*}{ Fatores } & \multicolumn{5}{|c|}{ Índices médios de velocidade de germinação diária } \\
\hline & \multicolumn{4}{|c|}{------ Concentrações de regulador vegetal $\left(\mathrm{mg} \mathrm{L}^{-1}\right)$------ } & \multirow[t]{2}{*}{ Médias } \\
\hline Cultivar & 0 & 100 & 200 & 300 & \\
\hline Capdeboscq & $0,005 \mathrm{bA}^{*}$ & $0,065 \mathrm{aA}$ & $0,059 \mathrm{aA}$ & $0,065 \mathrm{aA}$ & $0,047 \bar{A}$ \\
\hline Okinawa & $0,000 \mathrm{bA}$ & $0,026 \mathrm{aB}$ & $0,026 \mathrm{aB}$ & $0,038 \mathrm{aB}$ & $0,023 \mathrm{~B}$ \\
\hline Tsukuba & $0,000 \mathrm{cA}$ & $0,022 \mathrm{bB}$ & $0,051 \mathrm{aA}$ & $0,041 \mathrm{aB}$ & $0,029 \mathrm{~B}$ \\
\hline Médias & $0,001 \mathrm{C}$ & $0,038 \mathrm{~B}$ & $0,047 \overline{A B}$ & $0,049 \mathrm{~A}$ & \\
\hline \multicolumn{6}{|c|}{ Regulador vegetal } \\
\hline $\mathrm{BA}+\mathrm{GA}_{4+7}$ & $0,000 \mathrm{cA}$ & $0,060 \mathrm{bA}$ & $0,078 \mathrm{aA}$ & $0,081 \mathrm{aA}$ & $0,055 \mathrm{~A}$ \\
\hline $\mathrm{GA}_{3}$ & $0,003 \mathrm{bA}$ & $0,016 \mathrm{aB}$ & $0,016 \mathrm{aB}$ & $0,018 \mathrm{aB}$ & $0,013 \mathrm{~B}$ \\
\hline Médias & $0,001 \mathrm{C}$ & $0,038 \mathrm{~B}$ & $0,047 \mathrm{AB}$ & $0,049 \mathrm{~A}$ & \\
\hline
\end{tabular}

*Médias seguidas de mesma letra, minúscula na linha e maiúscula na coluna, não diferem entre si pelo Teste Duncan, ao nível de $5 \%$ de probabilidade.

Avaliando o efeito médio das diferentes concentrações de reguladores vegetais em relação a cada cultivar, verificou-se que para os cvs. Capdeboscq e Okinawa os tratamentos com os reguladores vegetais não diferiram significativamente entre si e tiverem maior $I_{V} G_{D}$ em relação tratamento testemunha. Para o cv. Tsukuba, os tratamentos com 200 e $300 \mathrm{mg} \mathrm{L}^{-1}$ não diferiram entre si, mas foram superiores em relação aos demais tratamentos (Tabela 2).

Entre os reguladores vegetais, o melhor desempenho do índice $I V G_{D}$ foi obtido com o BA + $\mathrm{GA}_{4+7}$ em todas as concentrações, exceto no tratamento testemunha. Os melhores $\mathrm{IVG}_{\mathrm{D}}$ para o $\mathrm{BA}+\mathrm{GA}_{4+7}$ foram 0,081 e 0,078 , nas concentrações de 300 e $200 \mathrm{mg} \mathrm{L}^{-1}$, respectivamente, sendo superiores ao tratamento com $100 \mathrm{mg} \mathrm{L}^{-1}$ e este foi superior à testemunha. Para o $\mathrm{GA}_{3}$, a testemunha teve o menor $I V G_{D}$ em relação aos demais tratamentos, que não diferiram entre si (Tabela 2).

Quanto à distribuição da germinação das sementes durante o período experimental, observouse que no cultivar Tsukuba o tratamento com o $\mathrm{GA}_{3}$ não foi suficiente para se obter uma porcentagem de germinação satisfatória. A porcentagem acumulada de germinação das sementes para esse cultivar chegou ao valor máximo de $20 \%$, quando tratados com $300 \mathrm{mg} \mathrm{L}^{-1}$ de $\mathrm{GA}_{3}$ (Figura 2). As sementes deste cultivar tratados com $\mathrm{BA}+\mathrm{GA}_{4+7}$ obtiveram as maiores porcentagens de germinação no tratamento com $200 \mathrm{mg} \mathrm{L}^{-1}$ aos 28 dias, alcançando $85 \%$ de sementes germinadas. $O$ tratamento com $300 \mathrm{mg} \mathrm{L}$ ${ }^{1}$ permitiu obter $70 \%$ de sementes germinadas, porém num período mais prolongado (42 dias) (Figura 1).

Nas sementes do cv. Capdeboscq tratados com $\mathrm{GA}_{3}$, a germinação estabilizou aos 42 dias, nas três concentrações do regulador vegetal, alcançando um percentual máximo acumulado de $45 \%$ de sementes germinadas no tratamento com $300 \mathrm{mg} \mathrm{L}^{-1}$ (Figura 2). O percentual acumulado de sementes germinadas alcançou o valor máximo (100\%) no tratamento com 200 e $300 \mathrm{mg} \mathrm{L}^{-1}$ de $\mathrm{BA}+\mathrm{GA}_{4+7}$ e em valor de $90 \%$ para o tratamento com $100 \mathrm{mg} \mathrm{L}^{-1}$, enquanto que no tratamento testemunha o porcentual de germinação foi nulo. 
Tsukuba/BA + $\mathrm{GA}_{4+7}$
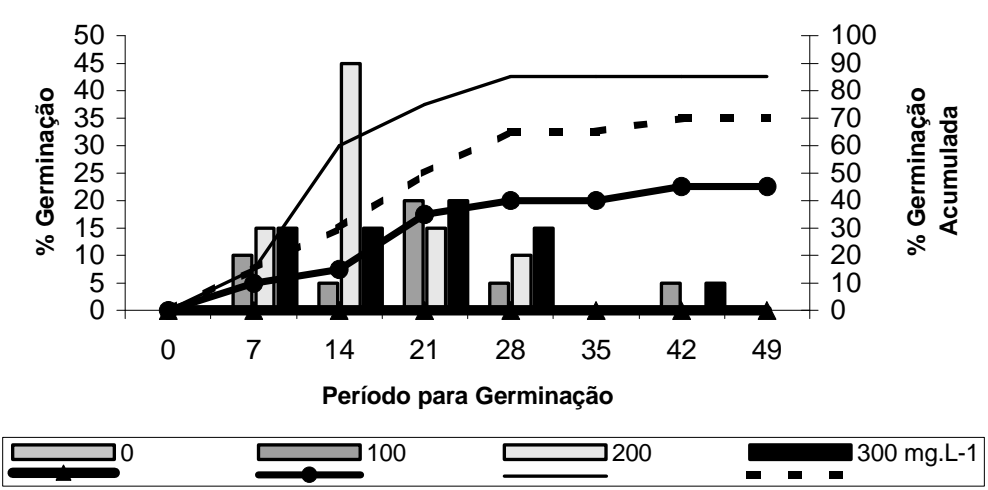

Capdeboscq/BA $+\mathrm{GA}_{4+7}$
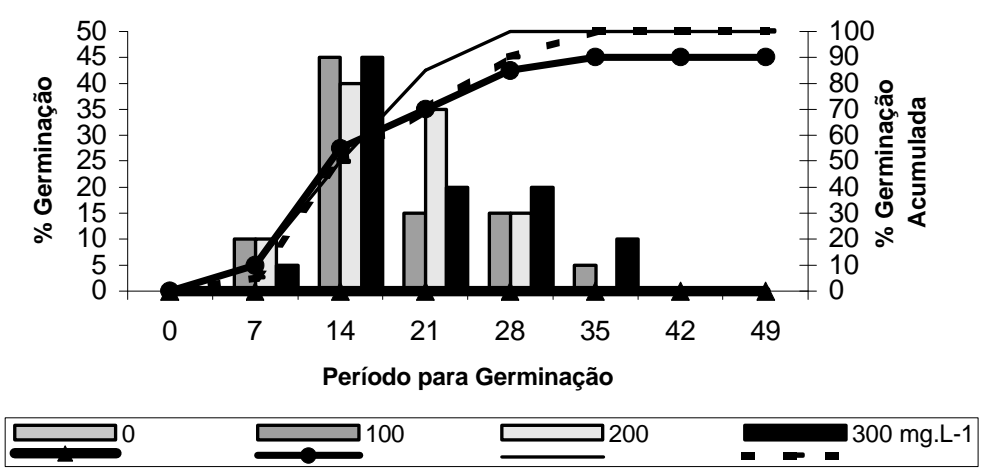

Okinawa/BA + $\mathrm{GA}_{4}+7$

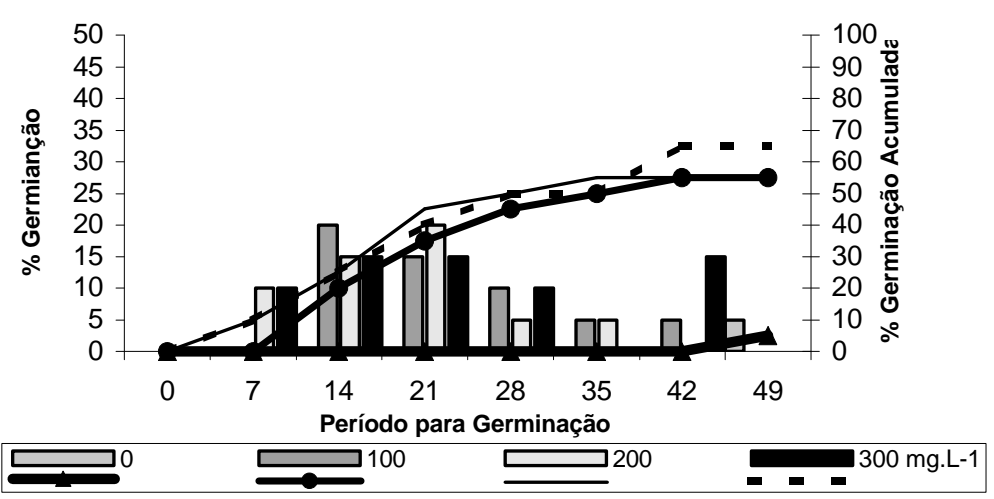

FIGURA 1 - Valores de germinação, em cada período de observação nas barras e acumulada nas linhas, de sementes dos cultivares dos porta-enxertos Tsukuba, Capdeboscq e Okinawa, tratados com diferentes concentrações do regulador vegetal $B A+\mathrm{GA}_{4+7}$. FAEM/UFPel, Pelotas-RS, 2005. 
PICOLOTTO, L. et al. Ação de giberelinas e citocininas...

\section{Tsukuba/GA}

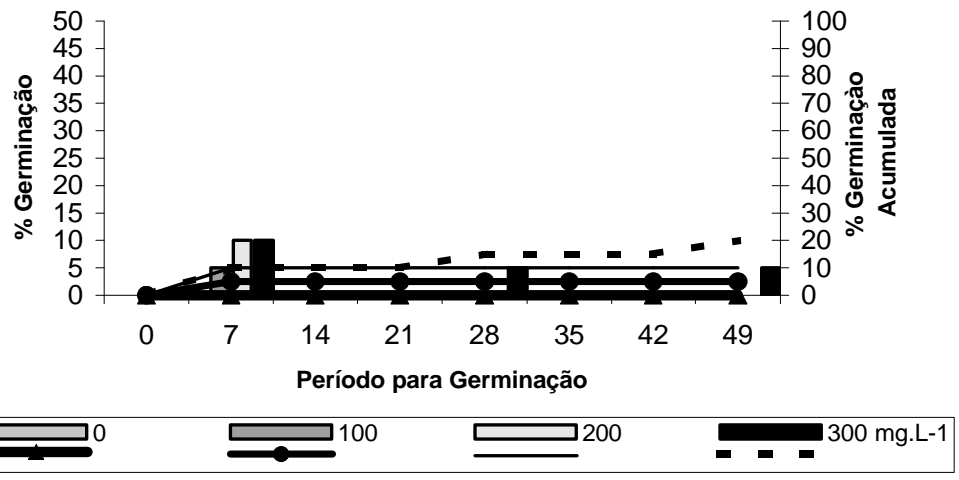

\section{Capdeboscq/GA}

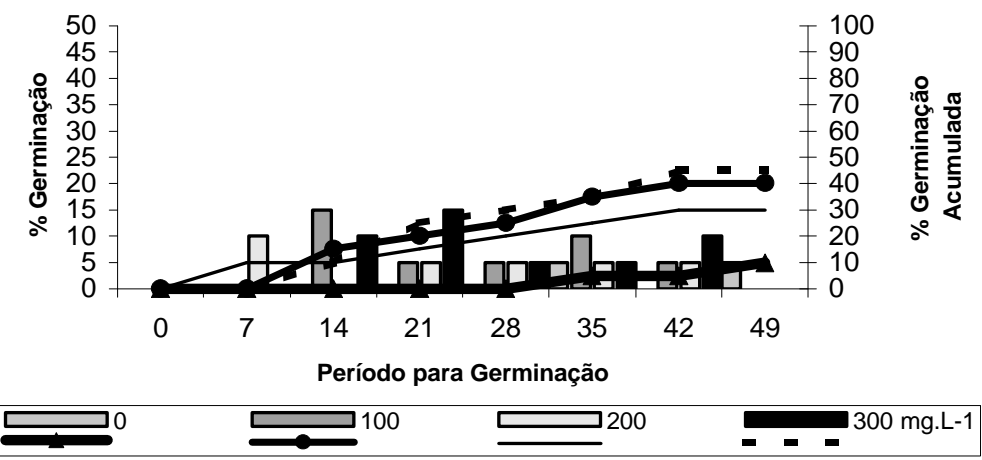

\section{Okinawa/GA}
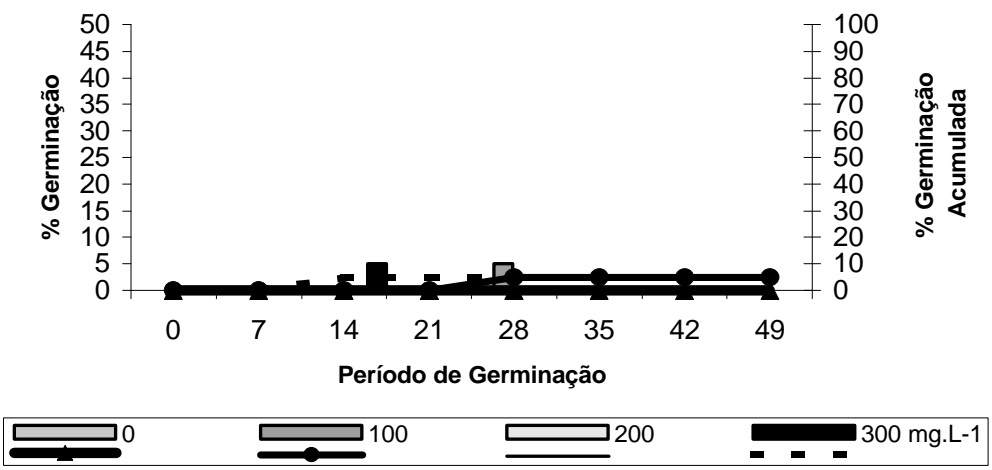

FIGURA 2 - Valores de germinação, em cada período de observação nas barras e acumulada nas linhas, de sementes dos cultivares dos porta-enxertos Tsukuba, Capdeboscq e Okinawa, tratados com diferentes concentrações do regulador vegetal $\mathrm{GA}_{3}$. FAEM/UFPel, Pelotas-RS, 2005. 
Para o cv. Okinawa, as sementes tratadas com o $\mathrm{GA}_{3}$ obtiveram uma germinação satisfatória aos 49 dias, alcançando um valor máximo acumulado inferior a $10 \%$ na concentração de 300 $\mathrm{mg} \mathrm{L}^{-1}$ (Figura 2). Ainda para este cultivar, no tratamento com $\mathrm{BA}+\mathrm{GA}_{4+7}$, a porcentagem de germinação foi superior as sementes tratadas com $\mathrm{GA}_{3}$ Nas sementes desse cultivar tratados com BA + $\mathrm{GA}_{4+7}$, obteve-se porcentuais acumulados de germinação entre $55 \%$ e $65 \%$, nos tratamentos com $100,200 \mathrm{mg} \mathrm{L}^{-1}$ e $300 \mathrm{mg} \mathrm{L}^{-1}$, respectivamente, enquanto que, na testemunha, a porcentagem acumulada de sementes germinadas não superou $5 \%$ (Figura 1).

\section{DISCUSSÃO}

Os cultivares Capdeboscq e Tsukuba tiveram comportamentos semelhantes quanto à porcentagem de sementes germinadas, porém, em todas as concentrações, o cultivar Capdeboscq se destacou. Segundo FINARDI (1998), o elevado porcentual de germinação, quando em condições adequadas, é uma característica das sementes do cv. Capdeboscq. FACHINELLO et al. (1995) associam a boa germinação ao fato deste cultivar ser de ciclo tardio, possibilitando uma boa maturação do embrião.

Comumente para a produção de portaenxertos os caroços são descaroçados permanecendo por um período de 3 a 4 meses em local sombreado (galpão) em temperatura ambiente. Após são semeados no mês de maio, chegando a uma germinação de aproximadamente $50 \%$ (FISCHER, Frutiplan Produção de Mudas, Pelotas, $\mathrm{RS}$, informação verbal). Entretanto, verificou-se nesse trabalho que o uso de reguladores vegetais permite obter maior porcentual de sementes germinadas. Com isso, quando se quer induzir a germinação das sementes logo após a colheita dos frutos, a aplicação de reguladores vegetais pode ser uma alternativa quando não se realiza estratificação, segundo BARBOSA et al. (1987) a dormência das sementes de pessegueiro pode ser interrompida pela ação de reguladores vegetais.

No cultivar Okinawa, a porcentagem de germinação obtida foi semelhante àquela encontrada por BARBOSA et al. (1987), que estudando a influência de períodos de estratificação e de ácido giberélico na emergência de plântulas do portaenxerto cv. Okinawa, obteve índices de emergência ao redor dos $15 \%$.

O comportamento germinativo dos cultivares tratados com $\mathrm{GA}_{3}$, pode estar relacionado com o grau de exigência hormonal mais específico para aquela espécie. Na maioria das espécies, a germinação está mais relacionada com as giberelinas, no entanto algumas espécies têm melhor germinação quando associadas a outros reguladores vegetais. No caso do pessegueiro, os resultados demonstraram que o uso de giberelinas associadas as citocininas é benéfico. Esses resultados concordam com o relato de BARBEDO e ZAIDAN (2004), os quais comentam que, além das giberelinas, as citocininas estão envolvidas na germinação.

Pela amplitude do período de germinação dos diferentes porta-enxertos, durante os 49 dias de avaliação, foi possível verificar que o $B A+G A_{4+7}$ tem um efeito muito mais pronunciado sobre a germinação das sementes, em relação ao $\mathrm{GA}_{3}$, pois para os cvs. Capdeboscq e Tsukuba a porcentagem de germinação foi superior a $85 \%$ aos 28 dias após o tratamento, diferentemente das sementes tratadas com $\mathrm{GA}_{3}$ ou, então, quando comparado ao sistema tradicional de plantio onde a germinação, segundo FINARDI (1998), inicia de julho a meados de agosto, 90 a 120 dias após a semeadura no campo.

Os maiores porcentuais de sementes germinadas dos porta-enxertos cvs. Capdeboscq e Tsukuba em menor espaço de tempo que o cv. Okinawa pode estar correlacionado a menor necessidade em frio destes cultivares para a superação da dormência, uma vez que existe certa co-relação entre estes fatores, ou então, às maiores concentrações de inibidores da germinação no tegumento da semente do cv. Okinawa, em relação às demais. Segundo BARBOSA et al. (1987), o cv. Okinawa necessita de, pelo menos, 30 dias de frio para a superação da dormência das sementes.

\section{CONCLUSÕES}

De acordo com os resultados obtidos no presente experimento conclui-se que:

- O uso de giberelinas e citocininas permite antecipar a germinação de sementes de portaenxertos de pessegueiro;

- O uso do $B A+G_{4+7}$ são mais eficientes na indução e antecipação da germinação de sementes dos porta-enxertos cvs. Capdeboscq, Tsukuba e Okinawa;

- A aplicação do BA + $\mathrm{GA}_{4+7}$ em sementes de pessegueiro aumenta a porcentagem de germinação e índices de velocidade de germinação, quando utilizado as concentrações de $200 \mathrm{mg} \mathrm{L}^{-1} \mathrm{e}$ $300 \mathrm{mg} \mathrm{L}^{-1}$. 
PICOLOTTO, L. et al. Ação de giberelinas e citocininas...

\section{REFERÊNCIAS}

1. AGRIANUAL. Pêssego. São Paulo: FNP Consultoria \& Comércio, 2004. p. 407-411.

2. BARBEDO, C.J.; ZAIDAN, L.B.P. Quebra de dormência em sementes. In: FERREIRA, A.G.; BORGHETTI, F. Germinação do básico ao aplicado. Porto Alegre: Artemed, 2004. p. 135-145.

3. BARBOSA, W.; CAMPO DALL ORTO, F.A.; OJIMA, M.; MARTINS, F.P.; RIGITANO, O. Emergência de plântulas do pêssego porta-enxerto Okinawa; influência de períodos de estratificação e de ácido giberélico. Bragantia, v. 46, n. 2, p. 435-441, 1987.

4. CHALFUN, N.N.J; HOFFMANN, A. Propagação do pessegueiro e da ameixeira. Revista Informe Agropecuário, v. 18, n. 189 , p. 23-29, 1997.

5. FACHINELLO, J.C.; TIBOLA, C.S.; PICOLOTTO, L.; ROSSI, A.; RUFATO, L. Produtividade e qualidade de pêssegos obtidos nos sistemas de produção integrada e convencional. Revista Brasileira de Fruticultura, v. 27, n. 1, p. 64-67, 2005.

6. FACHINELLO, J.C.; HOFFMANN, A.; NACHTIGAL, J.C.; KERSTEN, E.; FORTES, G.R. de L. Propagação de plantas frutíferas de clima temperado. Pelotas: Editora e Gráfica Universitária da UFPEL, 1995. 178 p.

7. FINARDI, N.L. Método de propagação e descrição de porta-enxertos. In: RASEIRA, M.C.B; MEDEIROS, C.A.B. A cultura do pessegueiro. Brasília: Embrapa-SPI, 1998. p.100-129.

8. FRAGA, A.C. Dormência de sementes. Informe Agropecuário, v. 8, n. 91, p. 62-64, 1982.

9. MARTINS, A.S. Propagação de porta-enxertos de pessegueiro por sementes e de cultivares de marmeleiro através de estaquia. Pelotas, 2005. 66 f. Dissertação (Mestrado em Agronomia) - Universidade Federal de Pelotas.

10. METIVIER, J.R. Dormência e germinação. In: FERRI, M.G. Fisiologia vegetal. São Paulo: Editora da Universidade de São Paulo, 1979. v. 2. p. 343-392.

11. METIVIER, J.R. Citocininas e giberelinas. In: FERRI, M.G. Fisiologia vegetal. 2. ed. São Paulo: EDUSP, 1986. v.2. p. 93162.

12. POPINIGIS, F. Fisiologia da semente. Brasília: Agiplan, 1977. p. 274-275.

13. SALISBURY, F.B.; ROSS, C.W. Plant physiology. Belmont: Wadsworth Publishing, 1992. 682 p.

14. SIMÃO, S. Tratado de fruticultura. Piracicaba: FEALQ, 1998. 760 p.

15. TAIZ, L.; ZEIGER, E. Fisiologia vegetal. Porto Alegre: Artmed, 2004. 719 p.

16. ZONTA, E.P.; MACHADO, A.A. SANEST - Sistema de análise estatística para microcomputadores. Pelotas: SEI n. 066060, Categoria A., 1995. 48 p.

Recebido em 20/09/2006 Aceito em 06/08/2007 